\title{
Supplementary Material of
}

\section{Recent changes in summer Greenland blocking captured by none of the CMIP5 models}

Edward Hanna ${ }^{1}$, Xavier Fettweis ${ }^{2}$, and Richard J. Hall ${ }^{1}$

${ }^{1}$ School of Geography and Lincoln Centre for Water and Planetary Health, University of Lincoln, UK

${ }^{2}$ Laboratory of Climatology, Department of Geography, University of Liège, Liège, Belgium

Correspondence: Edward Hanna (EHanna@lincoln.ac.uk) 


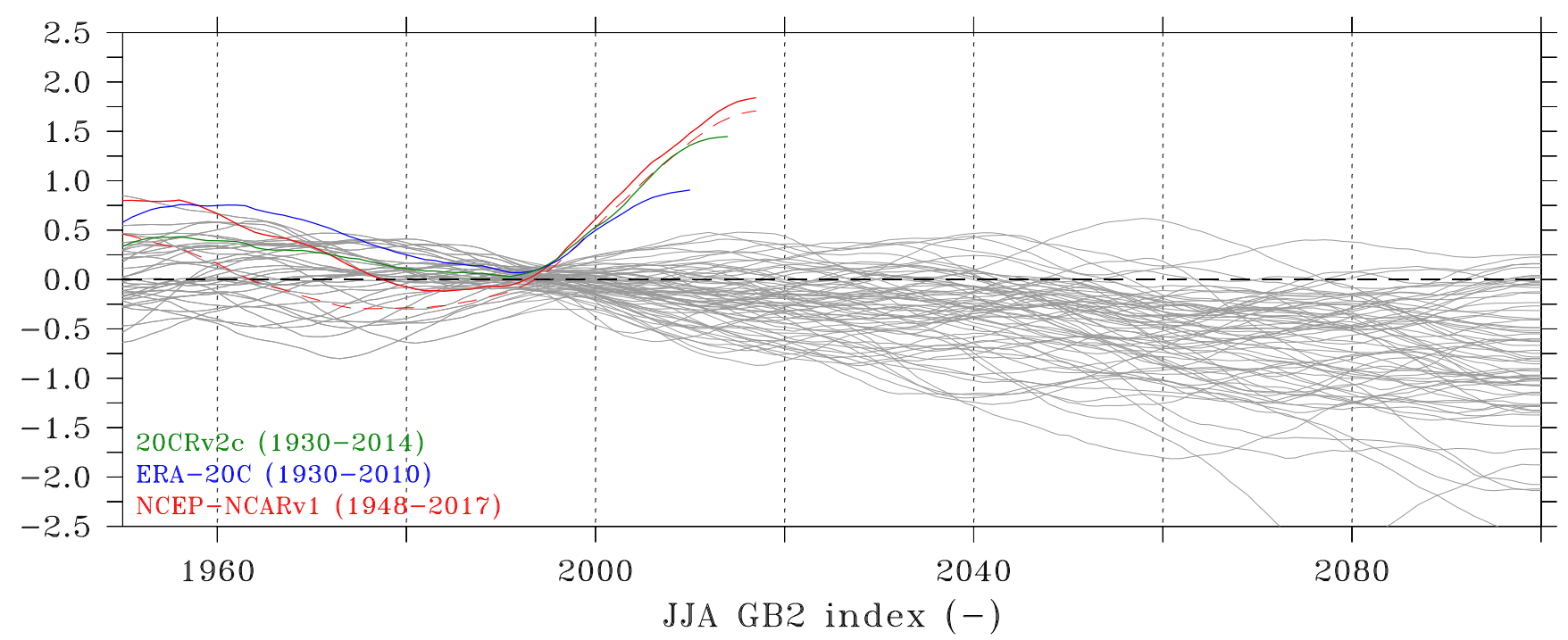

Figure S1. Same as Figure 1 but using a 30-year running mean.

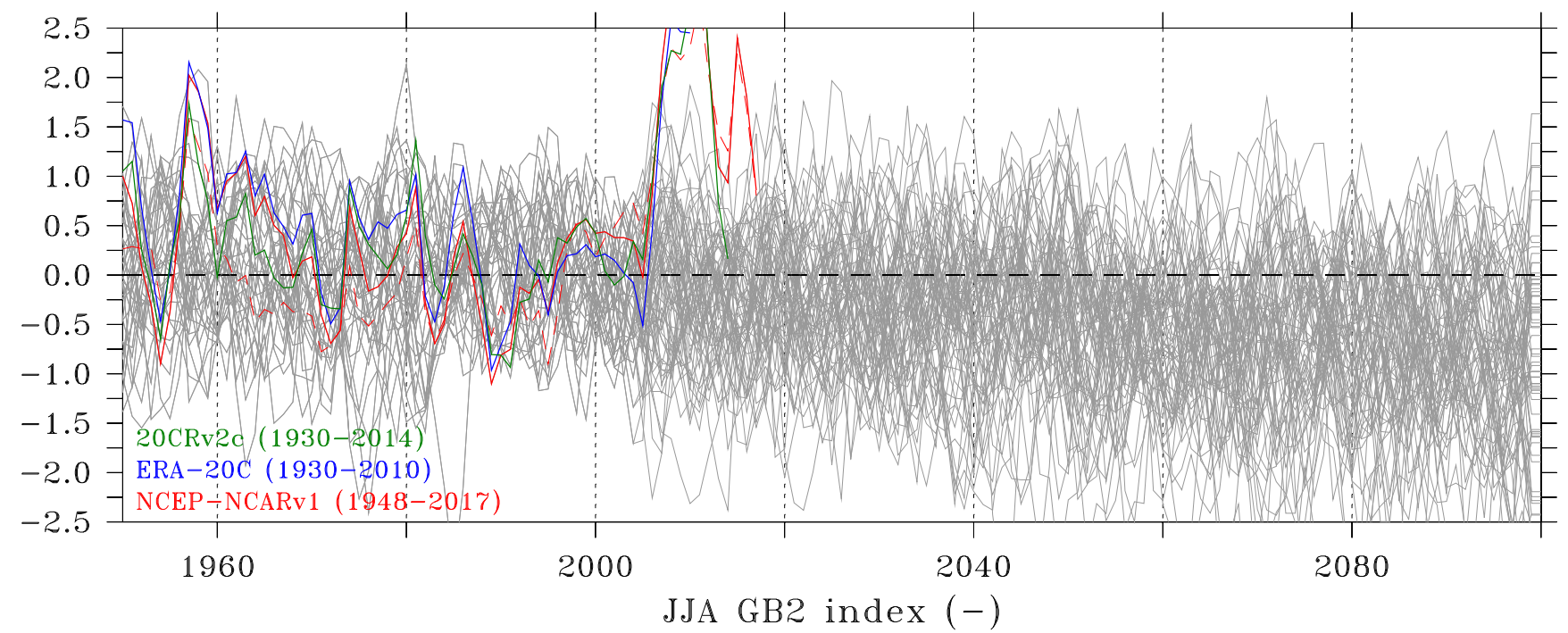

Figure S2. Same as Figure 1 but using a 3-year running mean. 
Table S1. List of the 36 CMIP5 global models (run r1i1p1) used in this study.

\begin{tabular}{cc}
\hline Model name & Model name \\
\hline ACCESS1-0 & GISS-E2-H \\
ACCESS1-3 & GISS-E2-R-CC \\
bcc-csm1-1-m & GISS-E2-R \\
bcc-csm1-1 & HadGEM2-AO \\
CanESM2 & HadGEM2-CC \\
CCSM4 & HadGEM2-ES \\
CESM1-BGC & inmcm4 \\
CESM1-CAM5 & IPSL-CM5A-LR \\
CMCC-CM & IPSL-CM5A-MR \\
CMCC-CMS & IPSL-CM5B-LR \\
CNRM-CM5 & MIROC5 \\
EC-EARTH & MIROC-ESM-CHEM \\
FGOALS-g2 & MIROC-ESM \\
FIO-ESM & MPI-ESM-LR \\
GFDL-CM3 & MPI-ESM-MR \\
GFDL-ESM2G & MRI-CGCM3 \\
GFDL-ESM2M & NorESM1-ME \\
GISS-E2-H-CC & NorESM1-M \\
\hline
\end{tabular}

